\title{
Effective Management of Invasive Plants
}

\section{By Nora Devoe, Bob Nowak, and Scott Florence}

S peakers at Workshop III, Effective Management of Invasive Plants, were Travis Bean, University of Arizona; Gordon Brown, National Invasive Species Council; John Randall, The Nature Conservancy and University of California, Davis; and Barron Orr, University of Arizona. Each speaker identified barriers to effective management of invasive plants and components of successful interventions. Exotic grasses have displaced native plant communities over large areas of North America's semideserts and deserts. Problems posed by these large-scale invasions include altered fire regimes leading to ecosystem degradation, biodiversity and habitat loss, and declining economic values including those related to tourism.

\section{Emphasis on Social Dimensions of Land Management}

Speakers and workshop participants asserted that effective management of now-extensive populations of exotic plants requires social, economic, and ecological interventions. Travis Bean's case study of current buffelgrass (Pennisetum ciliare [L.] Link) management practices provided a good example of the need for collective organization and response.

Buffelgrass is dormant much of the year and is only green for 2 to 6 weeks following rain events. Postemergent herbicides are effective only during this narrow window when plants are green. One problem presented by this narrow window is the need for immediate response with trained labor, which is seldom available with such short notice. The current distribution of buffelgrass is unknown, further hindering timely response. Travis Bean recommended the creation of rapid response teams to treat invasions with a regional mapping and monitoring force to direct responses to the highest priority areas, usually invasion fronts. He also called for an information clearinghouse to track which areas have been treated and which treatments are effective or ineffective.

More scientific information on how to combat buffelgrass is needed. Information to develop phenological models predicting green-up of both invasive and native plant species using temperature and precipitation would facilitate a ready response. Bean also called for studies of herbicide effects, remote sensing to monitor dispersal rates and predict invasion pathways, and economic analyses of invasion consequences and control options. Mobilization of resources on the scale needed for effective control requires public engagement, and like many speakers, Bean equated effective control with collaboration across many segments of society.

Among the social responses suggested for successful management, Gordon Brown, Invasive Species Coordinator for the Department of the Interior, advocated a governmental strategy of "do no harm," avoiding actions that disseminate invasive plants and facilitate their spread. An example of good intentions gone wrong is buffelgrass, which differs from the annual brome grasses (Bromus spp.) that plague the Great Basin and Mojave deserts in that it is a perennial and was deliberately introduced for erosion control and its forage value. Bean reported that the USDA Agricultural Research Service has developed a cold-resistant cultivar of buffelgrass that promises to expand the potential range of buffelgrass both northward and farther upslope. ${ }^{1}$ Judging by the many posters and presentations addressing the use of the 'Frio' buffelgrass cultivar at the Society for Range Management 2009 Annual Meeting, this particular genie may already have left the bottle. "Do no harm" has broad utility in the fight against invasives; many conference speakers noted various phytosanitary practices that can prevent invaders from arriving in vulnerable areas, particularly following fires.

Like Bean, Gordon Brown emphasized the need to fully engage the public in the effective control of invasive species. Brown suggested the use of social networks to rapidly disseminate information with an emphasis on engaging and mobilizing young people to join the fight against invasive species. A vigorous citizen science program is needed to engage people and enlist their help in gathering data and volunteering their labor. As did others, Brown noted the need to involve politicians and the press in the fight against invasive species. He emphasized opportunities to encourage policies for invasive species management and increased resources for control under the Obama administration.

John Randall, director of The Nature Conservancy's Wildland Invasive Species Team, focused on strategically prioritizing the use of limited resources. The invasive species problem is greater than the resources currently available to 


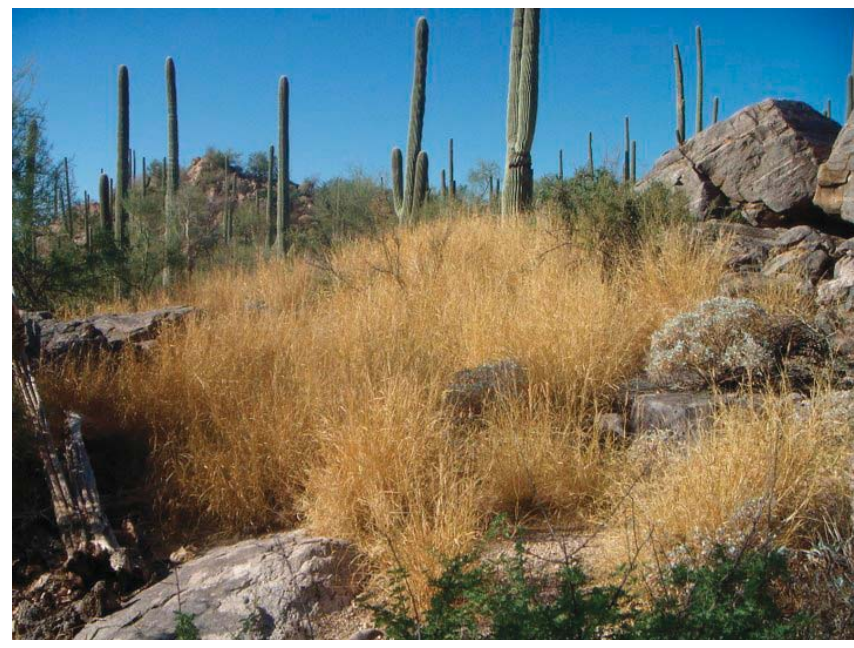

Invasives such as buffelgrass can effectively convert a fuel-limited system to one not limited by fuels or flammability. Photo taken along the Pontatoc Ridge trail on the south slope of the Catalina Mountains in Coronado National Forest, October 2007. Photo courtesy of Aaryn Olsson, Office of Arid Land Studies, University of Arizona, Tucson, Arizona.

address it. Therefore, society must agree on where and how to focus limited resources. Randall, too, called for largescale mapping and monitoring of plant invasions to facilitate effective response. The triage protocol he presented is shared by other land managers, and consists of 1 ) identification and protection of uninvaded areas and highest quality habitats that are likely to be invaded, 2) identification of areas with the greatest probability for successful restoration where actions can be taken to maintain at least a subset of valued native biota despite the presence of invaders, and 3) identification of areas where complete removal of invasives and replanting with desirable species would be necessary for restoration or else acceptance of new ecosystems in which the invasive species are a dominant component. Among the management tools Randall discussed were manipulations of ecosystem processes such as prescribed fire, alteration of soil nutrients to favor natives over invasives, and direct biological control of invasive species.

For Barron Orr, Geospatial Extension Specialist at the University of Arizona and Associate Director of the Arizona Space Grant Consortium, an essential social component of controlling invasive species is effective transfer of knowledge about invasive species and their ecosystem effects. Extension specialists can provide practical geospatial tools to locate and map invasive species. A lack of knowledge of these tools now impedes their use. Orr noted that software and database products are very often designed for one agency or user, when in fact a universal set of attributes would greatly facilitate a coordinated effort to control invasive species. "Collaborative mapping" can enable citizen science, volunteer involvement, and widespread coordination of management actions. Early detection and long-term, landscape-scale surveillance are two elements of effective invasive species management made possible with geospatial technologies. In addition, we must encourage the free sharing of data, software, and other tools.

All workshop speakers and many audience members identified people as the key to effective management of invasive species. "Involve all the neighbors," Bean said, "because if weeds are eradicated on one property, you don't want them re-entering from next door." A diversity of engaged stakeholders was identified as necessary for effective intervention. Among stakeholders named were elected officials, agencies, land managers, conservation organizations, students, volunteers, scientists, and businesses of many types such as insurance, real estate, landscaping, land development, and tourism companies that have a stake in reducing the risks and spread of invasive species. Media attention is necessary to keep the public focused on supporting control of invasive plants that stresses prevention with an early and sustained response to biological invasions.

Public engagement has to be continual rather than intermittent, as in a response to extensive wildfires. Successful management of invasive species requires persistence because a single land treatment is almost never enough. Multiple treatments and treatment combinations, such as herbicide applications followed by seeding, are often necessary. The public and its trustees must remain vigilant if invasive species are to be kept in check. Aggressive initial attack was identified as effective to control both weeds and wildfire. The advantage of knowing the distribution of invasive plants, and their probable dispersal, is that prioritized intervention can be planned and people can act rapidly.

\section{Effective Management Also Has an Economic Dimension}

The economic dimension of effective invasive species management involves knowing the costs and consequences

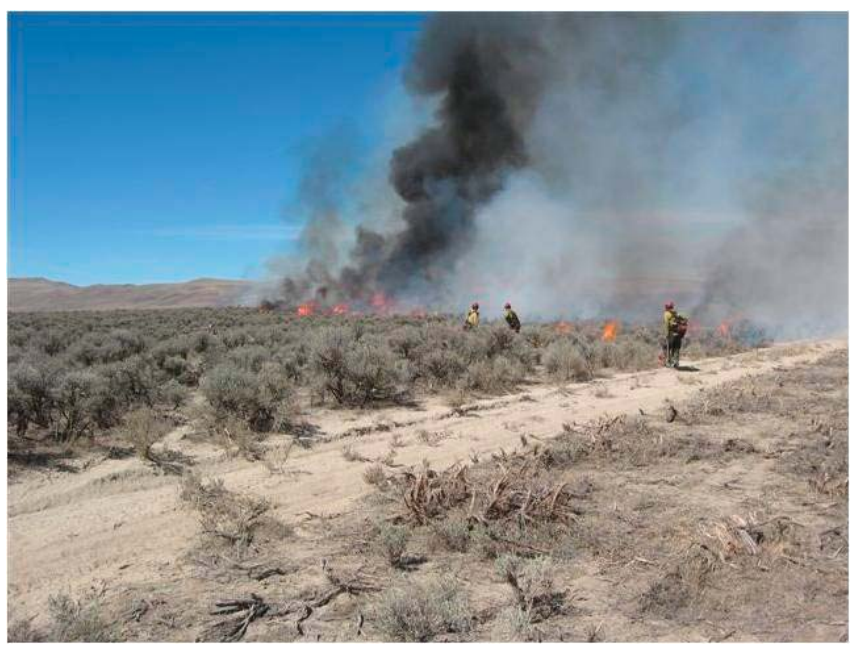

Prescribed fire, when used under the right conditions, can increase native bunch grasses in sagebrush communities. A perennial understory is a robust defense against cheatgrass invasion. Photo courtesy of the SageSTEP research program (see http://www.sagestep.org/). 


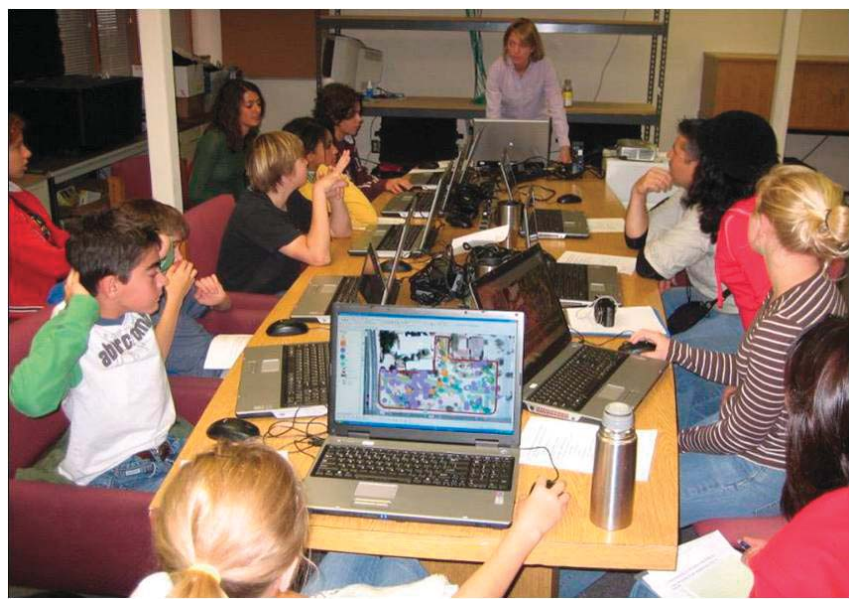

Young people can be engaged in the fight against invasive plants using geospatial tools. Photo courtesy of Barron Orr, Office of Arid Land Studies, University of Arizona, Tucson, Arizona.

of resulting ecosystem transformations. Communicating economic arguments is often a potent method for mobilizing decision-makers and the public. Several speakers suggested that public acceptability of weed treatments could be increased if people understood the costs and benefits of early intervention and the urgency of the situation in many areas. Because economic effects are often profound with pervasive social costs, nearly everyone becomes a stakeholder in combating invasive species. These important facts need to be articulated.

Initial response to invasive species is too often limited by economic considerations or lack of funds, although costs are relatively small compared to later stages when invasions are well established. Work remains to quantify the economic dimensions of invasive species and the invasive specieswildfire dynamic so that the public and their representatives have information needed to allocate public and private resources. Economics, as well as ecology, underlie the need to prioritize interventions, seeking the greatest benefit for our investment of limited resources.

Attracting additional resources to combat invasive plants was an economic need frequently named by the audience. One suggestion was that more applied research addressing invasive species issues in semiarid regions could be obtained using annual, topical solicitations similar to those used by the Joint Fire Science Program for fire and fuels issues. Travis Bean raised another economic issue, the need for a fiduciary agent to collect and hold funds to be used for early responses to plant invasions. The ability to accept public and private grants and donations could increase flexibility and timeliness when responding to plant invasions. For example, immediate response is usually needed following fire, when rapid revegetation is needed to discourage invasion. Government budget and procurement processes are often too slow for optimal response. Government budgets and programs may be stove-piped, limiting integration in response across programs and geographies. A fiduciary agent could facilitate action when it is most timely and cost-effective.

\section{Ecological Intervention is Multiphasic}

Restoration of ecosystem processes that lessen a plant community's susceptibility to plant invasion was recommended. Once invasive plant species are prevalent in a landscape, ecological restoration often requires a multistage process. The first stage involves the reduction or removal of invading plants and the liberation of resources needed for plant establishment and growth. Multiple disturbance agents, for example grazing followed by prescribed fire, may be needed to reduce invasive species. The next stages involve filling the liberated growing space with desirable species. The desired end composition may not be feasible without some intermediate facilitation, such as establishing exotic perennials that are sufficiently fire-resistant to break the frequent fire cycle, help restore basic ecosystem function, and provide a bridge to healthy native plant communities. These restoration processes may be iterative, such that invasive species are gradually reduced while natives are progressively increased. On many semiarid sites, merely reducing invaders without establishing desirable natives achieves only fleeting results.

Likelihood of success in invasive species management is increased when the site potential has been analyzed and explicit plans developed for restoring ecological processes required for conversion from invaded/degraded communities to restored native communities. Such plans might include determining how the desired germ plasm will arrive on the site and how it will be planted to persist and compete effectively with invasive species. A maintenance strategy may be necessary to sustain the restored community in the face of continued invasion pressure. Maintenance

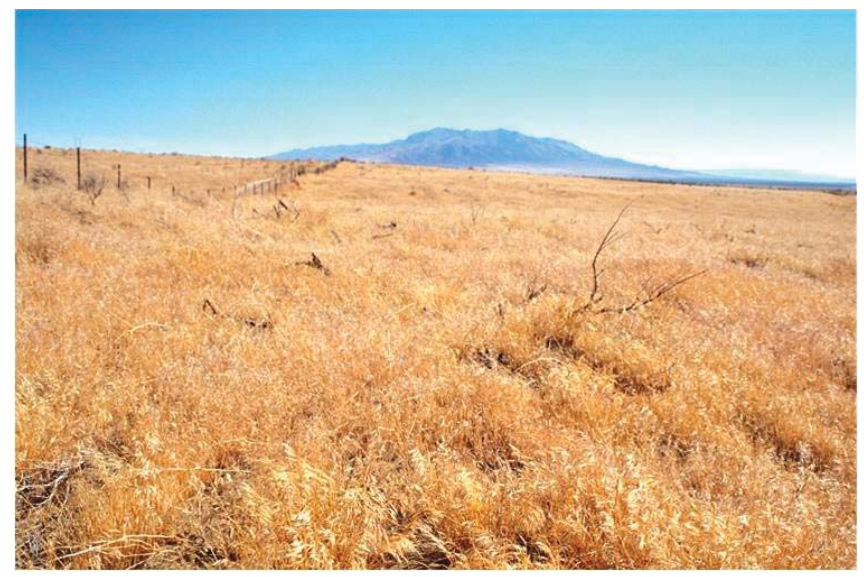

Cheatgrass (Bromus tectorum) is another invader whose impacts are recognized relatively widely. This annual grass has invaded vast areas of North America's Intermountain West, where it has changed the fire regime, promoting frequent fires that many native plants and animals cannot survive. Photo courtesy of John Randall, The Nature Conservancy, California Chapter, and Department of Plant Sciences, University of California, Davis, California. 
might involve fire protection or periodic burning in particular plant communities. Continued monitoring and appropriate response to adverse trends are part of effective maintenance.

Among the many interesting issues raised by participants was the question of tradeoffs in scale vs. effectiveness. Is it better to treat a very large area and only reduce invasive species populations by half, or to treat a smaller area and do everything necessary to eliminate the invaders and replace them with desirable species? If intensive treatment over a small area results in a long-term change, is this better than extensive treatment that may have only brief effects over a wide area?

The audience placed many items on the ecological wish-list of possible responses to the initial phases of plant invasions. Among these was detailed knowledge of the life histories of invading plants to enable exploitation of their vulnerabilities. For most invasions in arid and semiarid regions of the United States, technologies are needed to break patterns of recurring wildfires benefitting invasive plants. Mass production and broad dissemination of strong native competitors, including genotypes with transmissible ability to compete with invasive species, could retard reinvasion.

Workshop III participants stressed retaining all available tools for ecological management, including 1) both fire use and suppression, 2) herbicides, 3) biocontrol agents, 4) biopesticides, 5) mechanical removal or manipulation of invasive species, 6) use of native and introduced nurse plants, 7) planting, 8) seeding, and 9) phytosanitary controls that reduce introducing propagules of invasive plants to a site. Several participants called for the development of pre-emergent herbicides for widespread invasive species.

Sharing information across jurisdictions and organizational hierarchies is needed to compare experiences and address questions about the effectiveness of social, economic, and ecological interventions. Scientists and land managers identified common ground in the fight against invasive plants and the protection of arid land resources. Necessary next steps include the creation of social infrastructure to

- link regional invasive species centers in the American West,

- place arid and semiarid lands invasive species issues at the center of a national agenda for invasive species,

- more broadly engage the Western populace in the control of invasive plant species,

- coordinate invasive species mapping, monitoring, and management across land tenures and administrations,

- develop funding mechanisms for rapid response to new and expanding invasions, and

- support science initiatives targeting arid lands invasive species management, particularly interactions with fire, drought, and climate change.

\section{References}

1. Hussey, M. A., And B. L. Burson. 2005. Registration of 'Frio' buffelgrass. Crop Science 45:411-412.

Authors are Science Coordinator, Western Region, US Dept of the Interior Bureau of Land Management, Nevada State Office, 1340 Financial Blvd, Reno, NV 89502, USA, Nora_Devoe@ blm.gov (Devoe); Professor, University of Nevada-Reno, Dept of Natural Resources and Environmental Sciences, Reno, NV 89557, USA (Nowak); and Arizona Strip District Manager, Dept of the Interior Bureau of Land Management, Arizona Strip District Office, 345 E Riverside Dr, St. George, UT 84790, USA (Florence). 